\title{
Managing the
} communication channel.

Discursive representations of clinical communication in forensic psychiatric reports

Dariusz Galasiński ${ }^{1}$

Justyna Ziółkowska ${ }^{2}$ 


\section{ABSTRACT}

Background: Forensic reports require clinicians' presence as an agent in courtordered forensic assessment. Aim: We focus on discursive representations of clinical communication in forensic psychiatric reports. Methods: We perform a critical discourse analysis of 142 forensic assessment reports for 33 patients detained and hospitalized on forensic wards in three hospitals in the southwest of Poland. Results: Clinical communication is constructed as controlled by the clinician. All references to patients' communication are anchored in interpretation by the clinician. While the speaking patient is explicitly constructed as a communicator, the clinician her/himself is only very rarely represented as personally communicating, invoking an impersonal voice of institutional medicine. Discussion: Our study offers insight into the role of communication is forensic psychiatry as serving the clinician to construct an institutionally useful account of the patient. In contrast to psychiatry's pronouncements, communication is not a means for a clinical dialogue, but for an institutional monologue. Conclusion: The results of our qualitative study are useful as do not only examine how things are done in forensic psychiatry, but also what it means in its context.

\section{KEYWORDS}

Clinical communication, discourse analysis, forensic reports, psychiatry

\section{BIOGRAPHIES}

Dariusz Galasiński is Professor and head of the Centre for Interdisciplinary Research into Health and IIIness, University of Wroclaw Poland. His current research interests focus upon experience of mental illness, disability and suicide, and loneliness. Dariusz's recent books include Discourses of Men's Suicide Notes (2017, Bloomsbury) and Discursive Constructions of the Suicidal Process with Justyna Ziółkowska (2020, Bloomsbury).

Email: dariusz.galasinski@uwr.edu.pl. ORCID: 0000-0003-2247-922X.Twitter: @d_galasinski

Justyna Ziółkowska is Associate Professor in psychology, University of Social Sciences and Humanities (SWPS), Poland. Justyna's research focuses on discourse analysis of medical practices and experiences of mental problems. At present, she is studying representations of suicidal thoughts and attempts in individual 
and institutional discourses. Her latest monograph is Discursive Constructions of the Suicidal Process with Dariusz Galasiński (2020, Bloomsbury).

Email: jziolkowska@swps.edu.pl. ORCID: 0000-0001-8828-6047.Twitter:

@jziolkowska1 


\section{Introduction}

Forensic mental health services are predominantly described as driven by the bio-medical paradigm oriented toward impairment, biological reductionism, and physician-led treatment as well as decision-making (Livingston, Nijdam-Jones, \& Brink, 2012; Pouncey \& Lukens, 2010). Over the recent years, however, this approach has been changing and more attention has been paid to recognising participatory and collaborative approaches to patient care as more effective in mental healthcare provision (Barnao, Ward, \& Casey, 2015).

Yet, the nature of service provision in a forensic mental health hospital poses a series of challenges for delivering patient-centred care. For example, as Hettema (2019) suggests forensic psychiatry faces a significant conflict between its duty of confidentiality and that of reporting to the courts and other supervising bodies about various aspects of patients' wellbeing. Moreover, as patients can be admitted with diminished or absent responsibility, they might not have capacity to consent to treatment. Forensic psychiatry, finally, has the additional goal of preventing future illegal acts by the patient, while dealing with her/his suffering becomes a secondary goal (Hettema, 2019).

More generally speaking, forensic psychiatry is located at the interface between law and psychiatry and the goal of involuntary detention, which is of interest to us here, is both care of the patient and isolation of the offender. The forensic psychiatrist working in a mental health facility plays a double role, negotiating being a medic who cares for the patient, with being a representative of the penal system who protects the public (Stone, 1984; see also O'Grady, 2002, 2004). This creates a double bind for the doctors as they must provide psychiatric care and at the same time serve as objective evaluators (and witness experts) of the patient-inmate's progress $(\mathrm{Ng}, 2016)$, though it is argued that the patient remains at the centre of the forensic psychiatrist's care (Völlm et al., 2018).

\section{Psychiatric forensic reports}

In today's forensic psychiatry, the written report is the core of psychiatric evidence and goes beyond merely documenting how forensic psychiatric assessment was performed (Griffith, Stankovic, \& Baranoski, 2010), while at the same time being a result of intensive clinical work and interactions (Silva, Weinstock, \& Leong, 2003; Mossman et al., 2007). Indeed, psychiatric forensic reports serve many functions, including preparing grounds for testimony, facilitating treatment or demonstrating appropriate evaluation.

Griffith and colleagues (2010) suggest that forensic psychiatric reports are also a means of safeguarding against inappropriate interpretation, ambiguity or biased language. They see forensic reports in terms of revealing the evaluator's voice and suggest that by organising available information into a report, the clinician brings characters and events into a performative narrative for an intended audience. This process goes beyond a mere recounting of clinical findings. Instead, the forensic psychiatrist creates a written performance in an attempt to tell a compelling story (see Applebaum, 2010). Pointing to reports' narrative complexity present in many reports, the researchers argue for seeing the writing psychiatrists as characters in their own stories (Griffith et al., 2010). 
This view of psychiatric forensic reports seeks the clinician's presence in court-ordered forensic assessment and it is in particular clinical communication in which the writing clinician is constructed as an explicit or implicit agent. We are therefore interested in how forensic reports on current mental health state and progress in treatment of psychiatric patients detained in mental health hospitals construct clinicians as communicators and position them as part of collecting the evidence in the forensic psychiatric assessment process. We are particularly interested in representations of the channel of communication, access to it and how it is used by the communicating participants.

There is little research on texts of psychiatric forensic reports. What research there is has focused predominantly on psychiatric assessment and testimonies of experts before the court (Wettstein, 2010). Written reports have been seen as documentation of what was done and of the quality of psychiatric assessment (Gray-Little \& Kaplan, 1998; Grisso, 2006). Analyses of forensic reports' text has been limited to formal aspects such as composition or correctness (e.g., Greenfield \& Gottschalk, 2008; Pyrcak, 2010; Silva et al., 2003).

Research by Karlińska (2021) is the only study we found that explicitly focuses on reports as texts. She shows that the 65 forensic psychiatric reports contained forms described as dehumanising (Resnick \& Soliman, 2011) suggesting a distance from the patient, who, moreover, was rarely referred to by their surname. The authors' voice was limited, while the assessing clinicians avoided writing in the first person linguistically taking explicit responsibility for what they wrote. Karlińska suggests that such linguistic characteristics make the texts formal (Pennebaker, 2011) and are presented as objective and impartial.

In our study, which is based on the reports by Polish psychiatrists, we focus solely on representations of clinical communication. This is because the relationship between the therapist and the patient is a key component of healthcare and it is achieved through appropriate communication. Clinical communication is believed to be crucial to the effectiveness of healthcare, with significant effects on outcomes reported in quantitative studies (Kelley, Kraft-Todd, Schapira, Kossowsky, \& Riess, 2014; Riedl \& Schüßle, 2017). A good therapeutic alliance and rapport are assumed to be achieved by communication that focuses on the patient's concerns, on her/his involvement in decision making and on her/his feelings of being respected, important and taken seriously (Priebe et al., 2011; Stivers et al., 2018). This is particularly important in psychiatry given that communication has both diagnostic and specific therapeutic roles. Accordingly, communication skills are considered to be core psychiatric competences by professional organisations such as the Royal College of Psychiatrists, the World Psychiatric Association, the American Psychiatric Association or the American Board of Psychiatry and Neurology.

Although we have no access to what happens in the consultation, representations of communication which are made by psychiatrists show the role of communication in actual psychiatric care. First, in references to communication we access how the writing clinicians see their communication with the patient. We analyse reports of clinical communication from the point of view of the clinician and with the elements of the communicative process that the clinician considers important. Second, as it is communication with the patient that is the primary tool for gaining information about the patient and, in the process, in the diagnostic process, representations of communication offer insight into understandings of the tool.

Although we accept that the forensic psychiatrist plays a double role, as we suggested above, negotiating between the roles of a doctor performing healthcare with being a representative 
of the penal system protecting the public (Stone, 1984; see also O'Grady, 2002, 2004), more and more attention has been paid to recognising participatory and collaborative approaches to patient care as more effective in forensic mental healthcare provision (Barnao et al., 2015). In this context, it is interesting to consider how the reports construct clinical communication, and in particular its participants, the message and its channel.

\section{Methodology and data}

\section{National context}

In Poland, involuntary commitment is imposed when an individual committed a crime while insane, when the crime is considered socially detrimental in a significant way, and when the perpetrator is highly likely to commit a crime again. Depending on the nature of the crime and a host of other considerations (e.g., aggressiveness, escape risk), court-supervised appropriate preventive measures are applied for renewable periods of six months, while there is no set duration of the detention. In 2015, the Polish penal code introduced outpatient therapy as an alternative to inpatient detention, and currently, there are four types of preventive measures (three of which are non-custodial): 1) control of the current location with electronic devices, 2) outpatient therapy (psychological therapy, sex therapy, pharmacotherapy), 3) treatment of addiction, and 4) detention in psychiatric institutions (for an overview of the model of care for mentally disordered perpetrators, see Heitzman, Markiewicz, \& Gosek, 2019).

The decision to impose psychiatric detention is predicated on four principles: necessity, proportionality, obligatoriness and experts' opinions. Thus, detention in a psychiatric institution applies only to those situations where it is necessary to prevent the perpetrator from committing a further contravention of law with a significant negative social impact. In such a situation, the court, after hearing expert opinion, orders the obligatory application of a preventive measure (Gierowski \& Paprzycki, 2013). To determine the necessity of preventive measures, psychiatrists along with psychologists prepare written assessments of the current mental health state and progress in treatment at least every 6 months, based on the stipulation of the Polish Code of Criminal Procedure. Based on their opinion, the court decides on the continuation or revocation of preventive measures.

However, there are no clear standards for criminal responsibility evaluation in Polish psychiatry (Hajdukiewicz, 2016; Kacperska, Heitzman, Bąk, Leśko, \& Opio, 2016), with the guidelines which are open to interpretation. Hajdukiewicz and Heitzman (Jarema, 2007) recommend that the report should have four parts. After the introduction, there should be a report on the experts' activities (e.g., interviews, examinations) and their observations, then a discussion of the entire evidence base and conclusions which are supported by justifications, and finally, the conclusions discussing final assessments.

Karlińska (2021) writes that, as a genre, a forensic psychiatric is a result of writing practices in medical centres and teams of doctors. Indeed, studies of the reports suggest significant differences between texts, even from the same teams (Bogdanowicz \& Hajdukiewicz, 1997; Hajdukiewicz, 2006; Pyrcak, 2010).

Such studies suggest that the genre of the psychiatric forensic assessment report in Polish psychiatry is still negotiated and, at best, it is emerging and there is no generic textual frame 
which must or even should be followed by individual clinician-experts. This means, in turn, that the texts we examined are more reflective of clinical relevancies imposed by assessment teams on the clinical practices and, in particular, clinical communication.

\section{Data}

Our study is based on 142 forensic psychiatric assessment reports (Polish: opinia sqdowopsychiatryczna and opinia sqdowo-psychologiczno-psychiatryczna) selected from a dataset of 194 reports for the court included in medical documentation for 33 patients hospitalised on forensic wards after court decisions in two psychiatric hospitals approved to admit detained psychiatric patients in southwestern Poland.

The 142 reports consist of the following two types of recommendations:

a. continuing detention at the same security level $(n=126)$;

b. continuing detention at a different security level $(n=16)$.

In our study, we collected forensic reports concerning patients who met the following criteria: (1) current detention in a psychiatric unit, (2) approval for participation from the doctor in charge of the patient's therapy, (3) age at least 18 years, and (4) the provision of informed written consent to participate in the study. This resulted in 142 forensic assessment reports for 33 patients ( 28 men and 5 women) detained in basic secure wards. The assessed forensic patients had committed different offences: murder ( 8 participants), attempted murder ( 3 participants), assault (4 participants), family abuse (7 participants), rape (1 participant), possession of drugs ( 2 participants), criminal threats ( 2 participants), mugging, robbery, burglary, document forgery ( 4 participants), and child sexual abuse ( 1 participant). One participant was detained due to worsening of illness. Most of the forensic patients had a diagnosis of schizophrenia (28 people), two had a diagnosis of a substance use disorder, the next two had a diagnosis of intellectual disability, and one patient had a diagnosis of personality disorder.

The duration of patients' detention ranged from one to 183 months; for some, it was their first detention, while others had a history of more than 10 previous detentions and hospitalisations at different levels of security (from basic to high-security units). Their ages ranged from 22 to 69 years, with a mean value of 43.9 ( $S D=12.77)$. Some patients were lonely, with no social support, and some had a supporting family. However, the forensic reports were predominantly about men diagnosed with schizophrenia, which is in line with the characteristics of the overall population of detainees in Poland (Ciszewski, 1995; Ruzikowska, Tarczyńska, \& Walaczyna-Leśko, 2009).

The study was performed in accordance with the Declaration of Helsinki, with ethical approval obtained from the ethical committee of the Wroclaw Faculty of Psychology of the University of Social Sciences and Humanities (SWPS).

\section{The analytic process}

The analytic process consisted of two stages. The data were coded with the use of the MaxQDA software. We coded those fragments that referred to communicative actions of clinical personnel (for the most part, the authors of the reports) whose recipient was the 
patient. We were also interested in all fragments that referred to the actions of patients that targeted other clinical personnel. Two researchers coded separately the entries in the reports, and then compared coded fragments. We coded the entire texts of the forensic assessment reports.

To avoid free interpretation, we used a systematic and explicit analytical process guided by rules and described methods by Miles and Huberman (1994). A comparison of the coded entries allowed us to create the dataset for detailed discourse analysis, which was the second stage of the analysis.

A version of Critical Discourse Analysis (CDA) was used in the discourse analytic stage. The assumption underlying this method is that social reality is constructed through and within language and that language is designed to represent reality selectively imbued with decisions about how to arrange them. Each of these selections carries its share of implicit assumptions, so that the reality represented is ideologically constructed (Hodge \& Kress, 1993). It is also through discourse (i.e., practices of representation) that language users constitute social realities: their knowledge of social situations, the roles they play, their identities and relations with other social groups (van Leeuwen \& Wodak, 1999). No text, spoken or written, represents reality in a neutral or objective way, representation is never reality 'as it really is', rather reality is always viewed through the tinted lens of ideological assumptions (Fairclough, 1992; Barker \& Galasiński, 2001).

We take a text-oriented approach (Fairclough, 1992, 1995a, 2003). Thus, we focus upon the content and the form of stretches of discourse, with an interest both in the semantics and syntax of an utterance, as well as the functions of what is said or written within the local context, and the social actions thus accomplished. CDA can be used to account for lexical choices and grammatical forms as well as larger syntactic and textual patterns. We focused on the linguistic form of the forensic reports under analysis with an interest in semantics and syntax, as well as the functions of what was written within the local context.

We draw upon Halliday's functional linguistics where the lexico-grammatical form of utterances is foregrounded as a resource for constructing meaning (Halliday, 1994). We explore the ideational function of what assessment teams wrote but also focus on the content, relating it to the larger socio-institutional context, using a hermeneutic-like interpretation of discourses (Titscher, Meyer, Wodak, \& Vetter, 2000). We thus attempt to identify the ideological underpinnings of the forensic reports.

The data we show in the article were selected independently by the two researchers. We looked for extracts that were most typical of the corpus. In the article, we included all the fragments that were selected.

\section{Results}

\section{Channel of communication}

In this section we discuss constructions of the channel of communication. We understand the notion of the channel of communication as an opportunity (be it physical or symbolic) to establish communicative contact and, in the process, a communicative situation. That is to say, opening a channel of communication gives rise to a situation in which a communicator is 
able to share their meaningful message with at least one other communicator. The person who controls access to the communication channel effectively controls the opportunity to communicate.

Although clinical communication can be represented in many ways, in our data, the channel of communication is represented as almost exclusively managed by the clinician. This has two aspects. First, the data show a clear role of the clinician in opening the channel of communication, a role which is often represented in disciplinary terms. Second, it is also the clinician who maintains the channel as keeps it open.

Consider first the following extracts in which the opening of the communication channel is constructedi:

(1) The patient reports for the conversation after being summoned.

(2) [The patient] reports for interview after being summoned, no resistance.

(3) He reports to the surgery after being summoned, he picks up the conversation willingly.

(4) A conversation was carried out with the patient and he was informed that (...) he is making disciplinary problems on the ward.

(5) Escorted to the surgery, [the patient] sits down at the place pointed to. He reports" that he had arrived from a psychiatric hospital.

(6) When requested $d^{\text {iii }}$, [the patient] arrives for consultation without resistance, takes a seat.

Communication which is represented in the assessment reports can hardly be more asymmetrical. These typical examples construct clinical communication as fully in control of the clinician. The clinician's rights related to opening of the channel of communication are so broad that the communication can be forced upon the patient. Note that patients are not asked to communicate, they are summoned to appear for communication.

Notably, patients' compliance with requests to appear for consultation or interview are noted. Indeed, patients' communication in (3) and (5) imply responding. On the one hand, they are contributions to a communicative encounter which was initiated and started by the clinician. On the other hand, in extract (3), the clinician implies that communication already started for the patient to pick it up (Polish 'podejmuje' is used, which strongly makes the connotation). Extract (5), alternatively, through the use of 'report', not only reinforces the clinician's right to start a communicative event, but also underscores the institutional context in which such contributions are not unfettered.

Such constructions are consistent with typical explicit representations of ongoing communication, where patients are almost exclusively represented as responding to communicative demands, rather than making unfettered contributions to the communication during consultation. Consider the following extracts:

(7) Requested to be clearer about the number of hospitalisations, [the patient] reports that he was [hospitalised] twice.

(8) Questioned about the current mood: Now he is taking sedating medication.

(9) He confirms memory gaps.

(10) When questioned about somatic illnesses, he reports that he has a kidney illness.

(11) Confronted with [criminal] charges, [the patient] most frequently belittles them.

(12) Denies hallucinations. 
Whenever clinicians explicitly refer to their interaction with the patient, clinical communication is constructed as resulting from the clinician's prompts. Clinicians' contributions to the interaction are consistently focused on re-opening, or maintaining, the channel communication. Whenever clinicians refer to themselves as communicators, the goal of what they say is to elicit a response. All the extracts quoted above (7-12) imply a question or some other verbal challenge that needs to be responded to.

In other words, clinical communication in forensic reports is re-constructed as questionanswer session, an interrogation rather than a conversation in which both parties are free to contribute to its progress. Instead, the patient is consistently constructed as reacting to what their clinicians say. This is, incidentally, consistent with an earlier finding where, when asked about her conversation with her psychiatrist, a patient said that she had not talked to the doctor. The doctor asked questions and she answered (Ziółkowska, 2009).

As we indicated, such a picture of communication is reinforced by the use of verbs of speaking (see below) which indicated formality and instiutionality of communication. Verbs such as 'podaje' (the most frequently used, 'reports'), 'deklaruje' ('declares'), 'zgłasza' (also translated as 'reports') all strongly imply that the communication took place in an institutional context. As such, we would argue, such verbs connote (perhaps weakly) that what the patient said had been a result of a person in some authority demanding information.

Now, there was a very limited number of clinicians' reports of patient communication which was not represented as elicited by doctors' questions. Consider first the following fragment:

(13) During the consultation, he was making spontaneous verbal contact.

Quite extraordinarily, what seems to be a spontaneous contribution to a conversation is not represented as communication at all. Rather, the patient is described as making verbal contact. It is difficult to imagine making 'verbal contact' outside communicative activity, therefore such a record is quite ambivalent and hard to explain. It seems that representations of a positively communicating patient are undesirable and thus, they are not made. Indeed, representations of unsolicited patient communication are consistently evaluated negatively. Consider:

(14) During the diagnostic conversation, difficult contact with the patient, he was talking in very general terms about his experiences during worsening of the illness process.

(15) [The patient] reports for the consultation after being summoned, at times verbose, doesn't let the other party speak, weakly interested in responses.

We see the two extracts as asserting clinicians' control of the communication process. The patient is not free to narrate - the way they speak must be controlled, otherwise it will be assessed in negative terms. In extract (14) the patient is described as difficult to communicate with as he was talking too generally about his experiences, in extract (15), the patient is represented as talking too much and attempting to take control of the channel of communication. In such extracts, communication is not a free-for-all, patients are criticised for taking an opportunity to make their own stories.

In this section, we discussed access to the channel of communication in psychiatric assessment reports. The documents construct communication as in sole control of clinicians. The control is constructed at at least three levels. First, clinicians are constructed to have control over access to communication, second, they are represented as keeping the channel open with their questions, and finally, there are practically no references to patients' 
unsolicited communication and those made, are assessed with regard to clinicians' expectations of what how the patient should communicate.

\section{Interpreting communication}

In this section, we discuss constructions of what patients say. The reporting of someone's words is never a 'neutral' account of what $s /$ he said. The act of retelling something involves the speaker's control both of what is being retold as well as how the retelling is structured and organised, depending on the speaker's view of the world (Caldas-Coulthard, 1994). Furthermore, the reporting voice (Cook, 1992) may not be one which co-exists with the reported one, it may dominate it and, in the process, distort it. Fairclough (1995b; also Coulmas, 1986) adds that although the propositional content of what was said (the contents of the message) is expected to be rendered accurately, expectations as to how speakers using indirect speech interpret the message are quite ambivalent.

Moreover, indirect speech offers a large spectrum of dimensions along which what is paraphrased can be interpreted, from assessment of truth (e.g., 'claim'), through verbosity ('ramble'), to force of directiveness ('request') (see also Verschueren, 1980; Wierzbicka, 1987). In such a way, the spectrum offers those who report the opportunity to impose their perspective on what was said, indirect speech is the linguistic action in which "the reporter comes to the fore" (Holt, 2016).

We would like to start the discussion in the negative. The most striking aspect of the dataset we have is not what we found in it, but rather what we didn't. We approached the data for reported speech of patients with expectations that there will be two significant sets of indirect speech. On the one hand, we expected the writing doctors to offer more or less explicit interpretations of what patients said, but on the other hand, we also expected a significant number of reports of patients' words without a clear interpretation. In other words, in the latter set, we expected doctors to write using verbs such as 'say' or 'tell', possibly also 'express' or 'relates'.

We were wrong in our expectations. It turned out that the writing clinicians practically do not use non-interpretative verbs. There were very few instances where the speaking patient was rendered through reference to verbs merely indicating communicative action, or an act of telling a story.

Interestingly, the verb 'say' was used in very particular contexts. Consider one such example:

(16) He claims that he had a good relationship with his friends. He says: 'I was the king of the space.'

We suggest that the patient's words cannot be easily paraphrased; they cannot be interpreted easily, either. Thus, the clinicians prefer to 'play it safe' and use a direct quote. In other words, we argue that the reference to saying is not so much an attempt to access the patient's voice and represent it on its own terms, but rather it is an attempt to avoid having to interpret it. The other few similar quotes also included 'strange' statements which were hard to interpret, making our argument plausible.

Another aspect of the use of, for want of a better label, low-interpretation verbs is that they are used in the negative. For example, clinicians write:

(17) He doesn't express delusions. 
(18) ... persecutory attitudes have been reduced, the patient doesn't express them anymore.

Here, the verb 'wyrażać' ('express') is used and it is at the same interpretative level as 'say'. However, the verb is used to indicate absence and, arguably, absence does not need to be interpreted. The use of such verbs must also be seen alongside records such as:

(19) Doesn't betray suicidal thoughts.

where communication is reduced to the transfer of information, presence or absence of symptoms which are read off the patient by the clinician.

As we indicated, the overwhelming majority of speech reporting in one way or another imposes an interpretation on what patients say. There were a number of ways in which this was done. First, clinicians' interpretations included expressing scepticism over what was said. For example, verbs such as 'deceive', 'claim', 'deny', 'declare', 'negate' all connote a negative attitude towards what the patient said. Similar to that, second, were implications of trust in what the patient said - with verbs such as 'confirm', 'admit'. The next group, third, implies an effort the patient put into persuading the doctor, doctors used verbs such as 'explain', 'argue', dwell on', suggesting that what had been said, had to be given an additional account.

All those verbs clearly offer a perspective on what patients say, suggesting a preferred reading of what was said. Significantly, no evidence is ever offered for the interpretations recorded. They come with a clinical 'fiat', clinicians' decision to make sense of what they heard. Needless to say, such absence of any explanation or absence of the basis for the interpretation is indicative of complete control over clinical communication. The control is not only of the process, as we argued in the first section, but also of the content and how it is meant to be interpreted. It is worth noting that the documents we analyse become the institutional and legal truth and the control over communication is much more than simply clinical assertion of their communication rights.

In her rare study of patients' notes, Anspach (1988) suggests that expressions which ultimately show doctors' scepticism towards what the patient says result mostly from their training. Doctors are trained to make a distinction between subjective symptoms and objective signs which can be ascertained through diagnostic technology (such as, for example, blood tests). What Anspach suggests therefore, it seems, is that as doctors are socialised into a particular view of medicine, they also take on a set of practices which manifest themselves also through their use of indirect speech.

Such an analysis is convincing, but only up to a point where we accept that it is the assertion of the right of the communication process which seems to be the crucial dimension in reporting patients' words. By far the most frequent verb referring to speaking was the verb 'podac' (translatable as 'report'), which we already discussed above. We argued that the verb (alongside with the verb 'zgłaszać' which is also translatable as 'report') underscores that what the patient says is a result of questioning, and at the same time, it firmly situates the conversation in an institutional context.

The verb puts a firm frame on the clinical encounter and does not allow free-flowing communication. Patients are not represented to be there to chat, rather to do the bidding of the communicating clinician. As much as such representations must also result from socialisation and training, their sources must also be seen as the assertion of medical power and control over clinical communication. 


\section{Who is communicating?}

The final dimension of controlling the process of communication stems from constructions of those involved in communicating. There are two interrelated aspects of this. First, the communicating psychiatrists remove themselves linguistically from the process of communication. The assessment documents do not contain any information as to who was part of any clinical encounter. The clinical participants are backgrounded (i.e. removed from the explicit part of the message). Second, the assessment reports do not contain the explicit voice of the assessors, and other clinical personnel. Patients communicate into an interactional vacuum.

We would like to start again with what we did not find. In the assessment reports we analysed, we did not find a single reference to a clinical encounter in which the clinician would be constructed as explicitly present. Put differently, the writing experts never position themselves in an interaction with their patients. We never hear their voices, we never read what they actually said. References to communication from the clinicians are consistently without constructing them as communicating agents.

There are two ways in which clinicians' participation is represented. First, it is constructed through the use of passive voice or the impersonal form ${ }^{\text {iv }}$. The reports represent an action with a consistently removed agent. And so,

(20) Requested to be clearer about the number of hospitalisations, [the patient] reports...

(21) When questioned about somatic illnesses, he reports...

(22) Confronted with [criminal] charges, [the patient] most frequently belittles them.

Even though they construct a communicative event, such phrases (quoted in full in the first section above) the clinician-participant is removed from the account. This is particularly important as the documents we analyse are normally authored by three clinicians. This means that a unique clinician-communicator cannot be presumed.

The other way of backgrounding the communicating clinician is through the use of indirect speech quoting the patient's words. Such verbs as 'deny', 'admit', 'answer' or 'argue' imply that what the patient says is a response to what was said before, yet, neither what was said nor who said it are reported in the assessment report. Clinical encounters are consistently reported as a one-sided event as if only what the patient said were relevant.

Such constructions have at least two consequences. First, clinicians' contributions are implied to be mere elicitations of patients' words. They are neutral and transparent, implied not to have an agenda or perspective. There is no communicative or institutional position from which the clinician speaks, remaining 'neutral' and, one could argue, speaking with the voice of medicine, rather than that of an individual clinician. Removing the speaking psychiatrist, second, reinforces this and seemingly a firmer focus on the patient. In the process, such a strategy gives the impression of reporting facts as if they were outside the communicative context in which communication happened. 


\section{Discussion}

The overarching argument of this article is that clinical communication is constructed as fully controlled by clinicians. This has three aspects. First, we argue that the channel of communication and access thereto is constructed as strictly controlled by the clinician; only the clinician can open or close the channel of communication. Second, the clinician's control is not of access but also of what is communicated. In other words, whatever communication takes place over the channel, is consistently subject to more or less explicit interpretation by the clinician. Third, despite the previous two points, it is the speaking patient who is explicitly constructed as a communicator responsible for the quality of communication, while the clinician her/himself is constructed to speak with the impersonal voice of institutional medicine.

Constructions of clinical communication in the assessment reports are in contrast with the dominant psychiatric literature. Psychiatry recommends that clinicians must encourage and work with patients' experiences (e.g., MacKinnon, Michels, \& Buckley, 2006; Stanghellini, 2007). Only a conversation that allows an understanding of the patient and their problems is clinically valuable (e.g., Pridmore, 2000; Sullivan, 1970), while creating an opportunity to gain the patient's trust, satisfaction and compliance (Cooper-Patrick et al., 1999; Mellor et al., 2006). Moreover, and crucially, theorists commonly condemn focusing upon symptoms of diseases rather than on the suffering of patients (e.g., Haidet \& Paterniti, 2003).

We show that it is clinicians who open and close the channel of communication. This happens as a start to a clinical encounter and as a means to continue the conversation. There were no references to patients initiating communication with a clinician, and the typical communication from the patient is constructed as a response/answer. The control over the communication channel, second, manifests itself also through the power to interpret what patients say. Patients are almost never constructed as saying something, rather always a perspective is applied to their words. Communication is not a free-for-all activity and patients are not allowed simply to talk or chat. What they say is constructed as more or less strictly controlled.

The final aspect of the clinicians' constructed control of the process of communication is done through removing the speaking clinician from the explicit part of assessment texts. Clinicians' voices are never accessed (Hartley, 1988), which might be interpreted as implying that it is the voice medicine which is utilised. Through this, reports are constructed as relaying objective facts, rather than witness opinions.

We would like to finish with a few comments. In the introduction, we briefly mentioned the idea of seeing psychiatric reports as performative narratives. We would like to take the argument further and borrow the notion of performativity from how it was initially conceptualised. In his milestone lectures, Austin (1962) proposed that some utterances do not so much tell us about something, but, instead, they do something. And so, if you say, given right circumstances, 'I (hereby) take you to be my wife/husband', 'I sentence you to death.', or 'I name this starship Enterprise.' you actually do this; you get married, you sentence the person to die or you name a starship. But as Austin started with utterances in highly ceremonial and institutionalised circumstances, it quickly became clear that we also use such sentences in everyday situations (Searle, 1969). "I promise you.", "I forgive you", "I apologise" are all a promise, an act of forgiving, and an apology, respectively. 
You could also argue that forensic psychiatric reports are also such performative acts. Through them, their authors (mostly at the end of the report) make a recommendation as to what should happen to the person reported on. In other words, forensic psychiatric report is also a recommendation. Seen like this, the body of the report is aimed at making the case of the recommendation performative (they could be seen in terms of Austin's felicity conditions), they must be seen as supporting the case made by the clinician-witnesses. In other words, references to clinical communication must be seen as serving an institutionally useful account of the patient, and their relationship with the clinicians.

In such a way, our dataset offers insight into the role of communication as experienced by clinicians engaging in clinical encounters with patients they assess. And the picture of communication we see is far from the pronouncements of institutional psychiatry which urges clinicians to engage in a free dialogue with the patient both in a therapeutic and in assessment contexts (McCabe et al., 2013; Glancy et al., 2015). Such pronouncements would seem to suggest free-flowing narratives should be the core of clinical communication in psychiatry. Communication which depends on continual prompting from clinicians and which must be fitted into their expectations seems counteruseful, both in linguistic and psychiatric terms. However, our data suggest that patients' unsolicited communication is judged within clinicians' expectations. Such expectations provide a yardstick for what and how much patients can say. Such judgements are not explained and they are constructed as sufficient and final.

In the data we analysed, however, there are no reports of any dialogue, let alone unsolicited narratives that are encouraged by psychiatry. Communication and access to it are strictly controlled by the clinician, and there are practically no reports including patients' spontaneous talk. Communication is never represented as a means for a clinical dialogue, but only for an institutional monologue.

Now, it is worth stressing that we have no access to extratextual reality and we do not know what actually happens during the clinical encounter. We cannot even be certain that what is quoted in the reports was actually said by the patient (see our research on misrepresentation in clinical notes, Galasiński \& Ziółkowska 2013). What we have are legal documents in which communication is reported and, we can assume, it is reported as valid and desirable evidence for clinicians' statement of recommendation. This means that the representations of communication that are made in the reports must be seen by the writing clinicians not only as relevant, but also showing good practice.

Incidentally, the practices we uncover also reflect the bio-medical anchoring of forensic psychiatry. If clinicians' orient themselves towards impairment, biological reductionism, and physician-led treatment as well as decision-making, then free-flowing narrative is of secondary importance.

Yet, forensic psychiatry is moving towards patient-centred approach and reaching beyond its narrow bio-medical (Barnao et al., 2015). This means probably changing the practices it currently espouses, including those of how to communicate and how to report communication. Our study is meant to offer insight into how particularly practices of communication can be reflected on and where the direction of change might be.

Such reflection, finally, is particularly useful when underpinned by qualitative research, which offers an in-depth insight into the phenomena it studies. And so, in this article we not only 
examine how things are done in forensic psychiatry, but also what it means. This particular strength of qualitative research makes it an excellent intellectual companion for medicine, one which continues to be largely ignored.

\section{Acknowledgments}

This research was supported by the National Science Centre in Poland under Grant OPUS 2013/09/B/HS6/02796 


\section{References}

Anspach, R. R. (1988). Notes on the sociology of medical discourse: The language of case presentation. Journal of Health and Social Behavior, 29(4), 357-375. https://doi.org/10.2307/2136869

Appelbaum, K. L. (2010). Commentary: The art of forensic report writing. Journal of the American Academy of Psychiatry and the Law Online, 38(1), 43-45.

Austin, J. L. (1962). How to Do Things with Words. Clarendon Press.

Barker, C., Galasiński, D. (2001). Cultural Studies and Discourse Analysis: a dialogue on language and identity. Sage.

Barnao, M., Ward, T., \& Casey, S. (2015). Looking beyond the illness: Forensic service users' perceptions of rehabilitation. Journal of Interpersonal Violence, 30(6), 1025-1045.

https://doi.org/10.1177/0886260514539764

Bogdanowicz, E., \& Hajdukiewicz, D. (1997). Opinie sądowo-psychiatryczne wydane po obserwacjach szpitalnych w Polsce w latach 1995-1996 - ocena poprawności pod względem formalnym. Postępy Psychiatrii $i$ Neurologii, 6, 461-469.

Caldas-Coulthard, C. R. (1994). On reporting reporting: the representation of speech in factual and factional narratives. In M. Coulthard (Ed.), Advances in written text analysis (pp. 295-308). Routledge.

Ciszewski, L. (1995). Ogólna charakterystyka pacjentów wobec których stosuje się w szpitalach psychiatrycznych w Polsce środek zabezpieczający. Doniesienie wstępne. Postępy Psychiatrii i Neurologii, 4, 149-156.

Cook, G. (1992). The Discourse of Advertising. Routledge.

Cooper-Patrick, L., Gallo, J. J., Gonzales, J. J., Vu, H. T., Powe, N. R., Nelson, C., \& Ford, D. E. (1999). Race, gender, and partnership in the patient-physician relationship. JAMA, 282(6), 583-589.

https://doi.org/10.1001/jama.282.6.583

Coulmas, F. (ed.) (1986). Direct and Indirect Speech. Mouton de Gruyter.

Fairclough, N. (1992). Discourse and social change. Polity Press.

Fairclough, N. (1995a). Critical Discourse Analysis. Longman.

Fairclough, N. (1995b). Media Discourse. Edward Arnold.

Fairclough, N. (2003). Analysing Discourse. Routledge.

Galasiński, D., \& Ziółkowska, J. (2013). Managing information: Misrepresentation in the patient's notes. Qualitative inquiry, 19(8), 589-599. https://doi.org/10.1177/1077800413494346

Gierowski, K., \& Paprzycki, L. (2013). Niepoczytalność i psychiatryczne środki zabezpieczajqce. Zagadnienia prawno-materialne, procesowe, psychiatryczne i psychologiczne. C.H. Beck.

Glancy, G. D., Ash, P., Bath, E. P., Buchanan, A., Fedoroff, P., Frierson, R. L., ... \& Zonana, H. V. (2015). AAPL practice guideline for the forensic assessment. The journal of the American Academy of Psychiatry and the Law, 43(2 Suppl), S3-S53.

Gray-Little, B., \& Kaplan, D. A. (1998). Interpretation of psychological tests in clinical and forensic evaluations. In J. H. Sandoval, C. L. Frisby, K. F. Geisinger, J. D. Scheuneman, \& J. R. Grenier (Eds.), Test interpretation and diversity: Achieving equity in assessment (p. 141-178). American Psychological Association. https://doi.org/10.1037/10279-006

Greenfield, D. P., \& Gottschalk, J. A. (2008). Writing forensic reports: A guide for mental health professionals (1st ed.). Springer.

Griffith, E. E. H., Stankovic, A., \& Baranoski, M. (2010). Conceptualizing the forensic psychiatry report as performative narrative. The Journal of the American Academy of Psychiatry and the Law, 38(1), 32-42. 
Grisso, T. (2006). Evaluating competencies: Forensic assessments and instruments (Vol. 16). Kluwer Academic/Plenum Publisher.

Haidet, P., \& Paterniti, D. A. (2003). Building a history rather than taking one: A perspective on information sharing during the medical interview. Archives of internal medicine, 163(10), 1134-1140. https://doi.org/10.1001/archinte.163.10.1134

Hajdukiewicz, D. (2006). Ultima ratio stosowania środków zabezpieczających związanych z umieszczeniem w szpitalu psychiatrycznym. Psychiatria Polska, 4, 645-646.

Hajdukiewicz, D. (2016). Zagadnienia psychiatrii sqdowej cz.1. Podstawy prawne i medyczne. Instytut Psychiatrii i Neurologii.

Halliday, M.A.K. (1994). An introduction to functional grammar (2nd edition). Edward Arnold.

Hartley, J. (1988). Understanding News. Routledge.

Heitzman, J., Markiewicz, I., \& Gosek, P. (2019). Complementary Model of Long-Care in Poland as a Result of the Political Transformation, Law Reform and Service Changes in Forensic Psychiatry. In B. Völlm \& P. Braun (Eds.), Long-Term Forensic Psychiatric Care (pp. 287-300). Springer.

Hettema, P. (2019). Ethical Aspects of Long-Stay Forensic Psychiatric Care. In B. Völlm \& P. Braun (Eds.), LongTerm Forensic Psychiatric Care. Clinical, Ethical and Legal Challenges. (pp. 47-62). Springer.

Hodge, R. I. V., \& Kress, G. R. (1993). Language as ideology. London: Routledge.

Holt, E. (2016). Indirect reported speech in interaction. In A. Capone, F. Kiefer \& F. Lo Piparo (Eds.), Indirect Reports and Pragmatics. Interdisciplinary Studies (pp. 167-187). Springer.

Jarema, M. (2007). Zalecenia konsultanta krajowego w dziedzinie psychiatrii w sprawie struktury opinii sqdowopsychiatrycznej w sprawach karnych i cywilnych. Instytut Psychiatrii i Neurologii.

Kacperska, I., Heitzman, J., Bąk, T., Leśko, A. W., \& Opio, M. (2016). Reliability of repeated forensic evaluations of legal sanity. International Journal of Law and Psychiatry, 44, 24-29.

https://doi.org/10.1016/j.ijlp.2015.08.028

Karlińska, A. (2021). Textual strategies of forensic psychiatrists. A corpus-based analysis of how the language of psychiatry is reconciled with the language of law in polish forensic psychiatric opinions. International Journal of Law and Psychiatry, 74, 101652. https://doi.org/10.1016/j.ijlp.2020.101652

Kelley, J. M., Kraft-Todd, G., Schapira, L., Kossowsky, J., \& Riess, H. (2014). The influence of the patient-clinician relationship on healthcare outcomes: a systematic review and meta-analysis of randomized controlled trials. PloS one, 9(4), e94207. https://doi.org/10.1371/journal.pone.0094207

Livingston, J. D., Nijdam-Jones, A., \& Brink, J. (2012). A tale of two cultures: Examining patient-centered care in a forensic mental health hospital. Journal of Forensic Psychiatry \& Psychology, 23(3), 345-360. http://dx.doi.org/10.1080/14789949.2012.668214

MacKinnon, R. A., Michels, R., \& Buckley, P. J. (2015). The psychiatric interview in clinical practice. American Psychiatric Publishing.

McCabe, R., Healey, P. G., Priebe, S., Lavelle, M., Dodwell, D., Laugharne, R., ... \& Bremner, S. (2013). Shared understanding in psychiatrist-patient communication: Association with treatment adherence in schizophrenia. Patient Education and Counseling, 93(1), 73-79. https://doi.org/10.1016/i.pec.2013.05.015

Mellor, D., Davison, T., McCabe, M., George, K., Moore, K., \& Ski, C. (2006). Satisfaction with general practitioner treatment of depression among residents of aged care facilities. Journal of Aging and Health, 18, 435-457. https://doi.org/10.1177/0898264306286199

Miles, M. B., \& Huberman, A. M. (1994). Qualitative data analysis: An expanded sourcebook. Sage.

Mossman, D., Noffsinger, S. G., Ash, P., Frierson, R. L., Gerbasi, J., Hackett, M., ... \& Zonana, H. V. (2007). AAPL practice guideline for the forensic psychiatric evaluation of competence to stand trial. Journal of the American Academy of Psychiatry and the Law Online, 35(Supplement 4), 3-72.

$\mathrm{Ng}_{L}$ L.L. (2016). Forging steel from fire: emerging as a forensic psychiatrist. Academic Psychiatry, 14, 1-2. https://doi.org/10.1007/s40596-016-0519-x 
O'Grady, J. C. (2002). Psychiatric evidence and sentencing: ethical dilemmas. Criminal Behaviour and Mental Health: CBMH, 12(3), 179-184. https://doi.org/10.1002/cbm.495

O'Grady, J. C. (2004). Report writing for the criminal court. Psychiatry, 3, 34-36. https://doi.org/10.1383/psyt.3.11.34.53585

Pennebaker, J. W. (2011). The secret life of pronouns: What our words say about us. Bloomsbury Press.

Pouncey, C. L., \& Lukens, J. M. (2010). Madness versus badness: the ethical tension between the recovery movement and forensic psychiatry. Theoretical medicine and bioethics, 31(1), 93-105.

https://doi.org/10.1007/s11017-010-9138-9

Pridmore, S. (2000). The psychiatric interview: A Guide to History Taking and the Mental State Examination. Harwood Academic Publishers.

Priebe, S., Dimic, S., Wildgrube, C., Jankovic, J., Cushing, A., \& McCabe, R. (2011). Good communication in psychiatry-a conceptual review. European Psychiatry, 26(7), 403-407. https://doi.org/10.1007/s11017-010$\underline{9138-9}$

Pyrcak, M. (2010). Opinie sądowo-psychiatryczne przy orzekaniu środka zabezpieczającego z art. 94 k.k. analiza pod względem formalnym. Internetowy Przegląd Prawniczy TBSP UJ, 1(4), 65-74.

Resnick, P. J., \& Soliman, S. (2011). Draftsmanship. In A. Buchanan, \& M. A. Norko (Eds.), The Psychiatric Report: Principles and Practice of Forensic Writing (pp. 81-92). Cambridge University Press.

Riedl, D., \& Schüßler, G. (2017). The influence of doctor-patient communication on health outcomes: a systematic review. Zeitschrift für Psychosomatische Medizin und Psychotherapie, 63(2), 131-150.

https://doi.org/10.13109/zptm.2017.63.2.131

Ruzikowska, A., Tarczyńska, K., \& Walaczyna-Leśko, A. (2009). Internacja - i co dalej? Postępy Psychiatrii i Neurologii, 18(3), 307-310.

Searle, J. R. (1969). Speech Acts. Cambridge University Press.

Silva, J. A., Weinstock, R., \& Leong, G. B. (2003). Forensic psychiatric report writing. In R. Rosner (Ed.), Principles and practice of forensic psychiatry (2nd ed., pp. 31-36). Arnold.

Stanghellini, G. (2007). The grammar of the psychiatric interview. Psychopathology, 40(2), 69-74. https://doi.org/10.1159/000098486

Stivers, T., Heritage, J., Barnes, R. K., McCabe, R., Thompson, L., \& Toerien, M. (2018). Treatment Recommendations as Actions. Health Communication, 17, 1-10.

https://doi.org/10.1080/10410236.2017.1350913

Stone, A.A. (1984). The ethical boundaries of forensic psychiatry: a view from the ivory tower. The Bulletin of American Academy of Psychiatry and the Law, 12, 209-19.

Sullivan, H.S. (1970). MD The Psychiatric Interview. W. W. Norton.

Titscher, S., Meyer, M., Wodak, R., \& Vetter, E. (2000). Methods of text and discourse analysis. Sage.

Van Leeuwen, T., \& Wodak, R. (1999). Legitimizing immigration control: A discourse-historical analysis. Discourse Studies, 1(1),83-118. https://doi.org/10.1177/1461445699001001005

Verschueren, J. (1980). On speech act verbs. John Benjamins Publishing.

Völlm, B. A., Clarke, M., Herrando, V. T., Seppänen, A. O., Gosek, P., Heitzman, J., \& Bulten, E. (2018). European Psychiatric Association (EPA) guidance on forensic psychiatry: Evidence based assessment and treatment of mentally disordered offenders. European Psychiatry, 51, 58-73 https://doi.org/10.1016/j.eurpsy.2017.12.007

Wettstein, R. M. (2010). Commentary: Conceptualizing the forensic psychiatry report. The Journal of the American Academy of Psychiatry and the Law, 38(1), 46-48.

Wierzbicka, A. (1987). English speech act verbs: A semantic dictionary. Academic Press.

Ziółkowska, J. (2009). Doświadczenie choroby a kryteria diagnostyczne. Analiza dyskursu wywiadów psychiatrycznych z pacjentami ze wstępnymi diagnozami zaburzeń depresyjnych. Unpublished PhD thesis, Szkoła Wyższa Psychologii Społecznej, Wydział Zamiejscowy we Wrocławiu. 


\section{Endnotes}

'We quote only the English translation of the data. All extracts quoted here were separately translated by two researchers from the Polish originals and then compared for accuracy and consistency.

ii The original word in the report is 'podaje' (infinitive 'podać'), which is normally described with synonyms such as 'inform' or 'relate'. However, here it is used in the syntactical form with a subordinate clause following the verb, i.e. 'podać że' ('report that'). In such a form the verb has strong institutional and formal connotations. In other words, in such grammatical contexts, the verb is used only with reference to communication from organisations or people representing them, or people who communicate with them (e.g., courts or medicine). We shall pick up on that later on in the article.

iii Polish does not distinguish between 'request' and 'ask' and the verb 'prosić' can be translated in either way. Here there is no additional context to provide guidance. We chose 'request' in extract (6) because it is more consistent with accounts where patients are given no choice, such as 'summon'.

iv The impersonal form in Polish (verbs ending in -no, -to suffixes) has a similar function to the English passive voice (it is normally translated with the use of the form) in that they allow to represent someone's action without explicitly referring to them. 


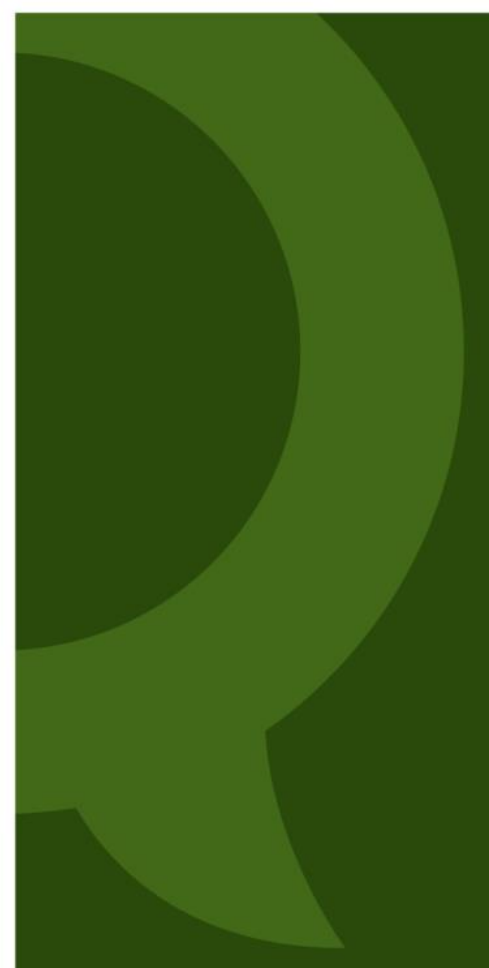

QUALITATIVE HEALTH COMMUNICATION

VOLUME 1, ISSUE 1, 2022 